\title{
PLANEJAMENTO DE AULAS PARA CONTEXTOS DIVERSOS: TRANSLINGUAGEM, MULTILETRAMENTOS E OS LETRAMENTOS CRÍTICOS
}

\author{
CLASS PLANS FOR DIVERSE CONTEXTS: TRANSLANGUAGING, \\ MULTILITERACIES AND CRITICAL LITERACIES
}

\author{
Alberto Eikiti Okaigusiku ${ }^{1}$ \\ Gabriela Claudino Grande ${ }^{2}$ \\ Fabiana Lacerda Vilaço ${ }^{3}$
}

\begin{abstract}
Resumo: Visto que a sociedade se relaciona com a linguagem de forma multissemiótica, o trabalho discute o ensino de língua inglesa a partir das perspectivas dos letramentos críticos, dos multiletramentos e da transliguagem, analisando 8 planos de aula do curso Comunicação Intercultural oferecido pelo Idiomas Sem Fronteiras. O artigo propõe reflexões acerca da relevância de tais teorias e suas contribuições para a prática docente e construção linguística, analisando e refletindo sobre as atividades e textos trabalhados em sala de aula, inclusive as produções finais no gênero podcast, nas quais a criticidade e o letramento digital tomam forma em textos de relevância social.
\end{abstract}

Palavras-chave: ensino de língua inglesa; letramentos críticos; multiletramentos; translinguagem; idiomas sem fronteiras.

Abstract: As society relates to language in a multisemiotic manner, this paper discusses English Language Teaching based on Critical Literacies, Multiliteracies and Translanguaging perspectives, analyzing 8 class plans from the course "Comunicação Intercultural" offered by the program "Language without Borders". The article proposes reflections about the theories' relevance and their contribution to teacher's practice and language construction, analysing and reflecting upon activities and texts used in class, particularly the final productions with the podcast genre, in which criticity and digital literacy take form in social relevant texts.

Keywords: English Language Teaching; critical literacies; multiliteracies; translanguaging.

\section{Introdução}

\footnotetext{
1 Graduando em Letras pela Universidade Federal do Mato Grosso do Sul (UFMS). E-mail: albertoeikitii@gmail.com

${ }^{2}$ Mestra em Linguística Aplicada pela Universidade Estadual de Campinas (UNICAMP). Especialista em Didática e Metodologia no Ensino Superior. Graduada em Letras Línguas Estrangeiras Modernas pela Universidade Estadual de Londrina (UEL). Trabalhou como pesquisadora visitante na Bond University com metodologia e ensino de Inglês para diferentes contextos. Docente na Universidade Federal do Mato Grosso do Sul (UFMS) no curso de graduação de Letras. E-mail: gabrielacgrande@ gmail.com

${ }^{3}$ Doutora em Letras na área dos Estudos Linguísticos e Literários em Inglês pela Universidade de São Paulo. Professora adjunta no curso de Licenciatura em Letras da FAALC/UFMS e coordenadora do projeto de pesquisa Literaturas e Estudos Culturais em Língua Inglesa: estudo de relações entre forma literária e processo sóciohistórico, e do projeto de extensão Rodas de Literaturas de Língua Inglesa. É membro da Poe Studies Association e do grupo de pesquisa Abordagens Teóricas e Práticas para uma Formação Crítica. E-mail: fabianavilaco@gmail.com
} 
A inexorável característica mutável de uma sociedade em rede (CASTELLS, 1999), associada a multissemioses relativas à linguagem, tida como híbrida, fluida e móvel (CANAGARAJAH, 2013), traz mudanças inevitáveis para ambientes educacionais, e sobretudo, para aqueles destinados ao ensino de línguas nomeadas ${ }^{4}$.

Pensando nisso, o presente artigo aborda a prática de ensino de língua inglesa como uma forma de (re)pensar o preparo e aplicação de aulas adequados aos contextos educacionais diversos e aos mais variados meios de produção de sentido. Desta forma, propomos uma reflexão sobre planejamento de aulas multimodais construídas por e para sujeitos ativos no processo de significação de sentido, entendendo o diálogo com a língua adicional ${ }^{5}$ a partir das perspectivas dos letramentos críticos, da translinguagem e dos multiletramentos.

As práticas analisadas referem-se às aulas ministradas dentro do curso Comunicação Intercultural para o ensino de inglês do programa Idiomas Sem Fronteiras ${ }^{6}$ (IsF) da Universidade Federal de Mato Grosso do Sul (UFMS). As teorias utilizadas, referência no treinamento dos professores e das aulas do curso de graduação de Letras, tanto no preparo, como na análise realizada, colaboram para uma construção linguística que amplia o diálogo retórico entre o acadêmico e as questões sócio-históricas e culturais que englobam os sujeitos.

Frente aos desafios lançados aos professores de línguas, e ancorados por uma abordagem teórico-metodológica transdisciplinar, na área de Linguística Aplicada, o nosso objetivo é analisar, de forma qualitativa-interpretativista, os processos de preparação e utilização de textos multimodais, evidenciando o papel desses recursos, em particular os digitais por meio das novas Tecnologias da Informação e Comunicação (TIC), bem como o papel dos temas selecionados para promover discussões que pudessem colaborar na construção e ampliação do repertório linguístico e social do aprendiz de língua adicional. Com esse propósito, a próxima seção apresenta uma breve contextualização bem como a metodologia da pesquisa; seguida por aspectos teóricos que dão suporte ao trabalho; depois discutiremos, em

\footnotetext{
${ }^{4}$ Entendemos línguas nomeadas como normas construídas socialmente e externamente, sendo tais normas “impostas" aos falantes (TURNER \& LIN, 2017, p. 2).

${ }^{5}$ Preferimos o termo língua adicional (em vez de língua estrangeira) sinalizando para o entendimento de uso da língua de forma horizontal, implicando a igualdade de condições e poder entre falantes nativos e não nativos, já que o aprendiz irá utilizar a língua "estrangeira" para interagir no próprio contexto, não sendo assim um “estrangeiro". A utilização desse termo também ressalta que há uma reflexão, por parte de aprendizes e educadores, com relação ao que é a língua, "de quem ela é e de quem pode ser, a que ela serve e o que cada um tem a ver com ela” (SCHLATTER \& GARCEZ, 2009).

${ }^{6} \mathrm{O}$ principal objetivo do Programa é promover ações em prol de uma política linguística para a internacionalização do Ensino Superior Brasileiro, valorizando a formação especializada de professores de línguas estrangeiras. (retirado do site do IsF. Acesso em 15 de outubro de 2018: http://isf.mec.gov.br/programa-isf/entenda-o-isf).
} 
forma de análise, os 8 planos de aula e sua relevância diante de perspectivas educacionais contemporâneas; e, por fim, as considerações finais.

\section{Metodologia e Contextualização}

O programa IsF propõe, dentre outras ações voltadas à internacionalização, aulas de línguas adicionais modulares para fins acadêmicos; os cursos variam de 16 a 64 horas por curso. Os discentes do programa podem apresentar níveis de proficiência diversos, do A2 ao C1. A proficiência deles é levada em conta para ingresso no IsF, uma vez que no ato da inscrição os discentes só podem se inscrever em cursos que compreendam seu próprio nível. O nivelamento pode ser realizado por meio da nota obtida no TOEFL, ou feito através de uma plataforma online, o My English On-line, financiada pelo MEC e disponível a qualquer discente ou servidor de instituições públicas de ensino superior.

Os professores do programa são, preferencialmente, estudantes do curso de Letras que passam por uma espécie de residência pedagógica ao participarem ativamente do programa. $\mathrm{O}$ acadêmico-professor, responsável pelo curso de Comunicação Intercultural e participante ativo da presente pesquisa, André ${ }^{7}$, cursava o último semestre do curso de licenciatura em Letras português e inglês, enquanto lecionava 3 cursos do IsF. André é professor de língua inglesa em cursos de línguas na cidade de Campo Grande há 3 anos e, mais recentemente, tem se dedicado aos projetos de extensão para o ensino de língua inglesa da Universidade Federal de Mato Grosso do Sul.

Antes do início da pesquisa, o acadêmico-professor André assinou um Termo de Consentimento livre e esclarecido. Além da análise qualitativa dos planos, conduzimos diversas entrevistas detalhadas com a descrição de cada uma das aulas ministradas para melhor compreensão dos processos envolvidos na preparação de suas aulas. Assim, e tomando as análises dos dados de forma interpretativista e qualitativa, propondo uma metodologia transdisciplinar e transcultural, a pesquisa realizada explorou os planos de 8 aulas ministradas no curso de Comunicação Intercultural, cujos alunos tinham nível B2 ${ }^{8}$ de proficiência em língua inglesa, dentro do Programa IsF da UFMS. Desta maneira, investigamos os processos

\footnotetext{
7 Os nomes aqui utilizados são fictícios e protegem o anonimato dos participantes conforme o Termo de Consentimento livre e esclarecido utilizado.

8 O nível B2 se refere ao European Framework of Reference for Languages (Quadro Europeu Comum de Referência para Línguas). Entende-se que o aluno que se encaixa nesse nivelamento tem como características entendimento inclusive de textos de caráter técnico, compreendimento de temas mais abstratos e contemporâneos na leitura, fala com suficiente grau de fluência e naturalidade, podendo interagir com nativos sem muito esforço por parte dos interlocutores. Esse nivelamento é necessário para ingresso nos cursos do Idioma Sem Fronteiras, agrupando os alunos em turmas de nível aproximado.
} 
metodológicos bem como perspectivas educacionais que perpassam a prática do docente do curso que contou com carga horária de 16 horas presenciais, sendo 4 horas por semana.

Os discentes, ao total 11, do referido curso, advinham de áreas distintas, evidenciando não apenas o pluralismo das práticas de letramento que já os acompanhavam, como a diversidade de uma sala de aula de um programa universitário. O gráfico a seguir mostra as áreas dos participantes, o que auxilia na justificativa das análises posteriores, na necessidade de letramento hipermidiático e na reflexão das discussões feitas em sala.

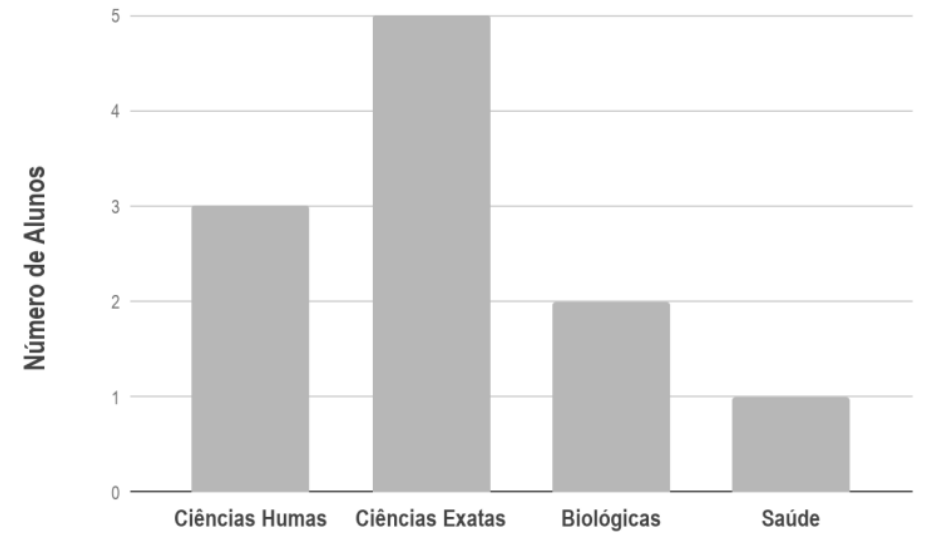

Gráfico 1 - Distribuição dos discentes do curso de acordo com suas áreas de atuação

É interessante notar que quase metade dos alunos da turma estavam matriculados em cursos da área de ciências exatas (5 alunos), enquanto os demais estavam distribuídos em cursos das ciências humanas ( 3 alunos), da biologia ( 2 alunos) e da área da saúde (apenas 1 aluno). O contexto diverso apresentado evidencia a necessidade de se reconhecer os diferentes processos de letramento em que os alunos já estão inseridos mesmo antes do ingresso no curso, além de prováveis contextos sócio-históricos bastante distintos entre si. Portanto, entender a língua por uma perspectiva em que se reconhece a maneira diversa de construção de sentido se torna essencial, explorando os recursos diversos de significação, como o vídeo, a música e os podcasts, e utilizando-os para promover o pensamento crítico e impulsionar o aprendizado de línguas.

Assim, e conforme relatado por André, após a divulgação do edital que permite inscrições no curso para a comunidade interna da UFMS, a ementa do curso homologada pelo Ministério da Educação foi estudada antes da preparação das aulas. Nela já estão previstos: a "familiarização com contextos de interação em ambientes culturais e acadêmicos em seus diversos canais de comunicação" (BRASIL, 2017), dando sentido ao uso de recursos midiáticos; e também o trabalho com tópicos sensíveis em determinadas culturas (política, 
religião, pluralidade de povos, etc). Estudada a ementa do curso, a decisão por trabalhar com base nos estudos de letramentos críticos, translinguagem e multiletramentos nos leva à etapa do preparo das aulas, o qual será analisado após o referencial teórico, a seguir.

\section{$2 \mathrm{O}$ entrelaçamento entre os letramentos críticos, os multiletramentos e a translinguagem dentro de sala de aula}

Os desafios da globalização e do mundo multimodal implicam em drásticas mudanças para o ensino contemporâneo, fazendo com que os multiletramentos impulsionassem mudanças que implicariam em uma negociação contínua de variedades de linguagem e discurso, possivelmente usando o inglês como língua franca ${ }^{9}$ sem favorecer assim, este ou aquele dialeto. Os multiletramentos propõem também a transgressão de práticas tradicionais de ensino, encorajando o uso de formas híbridas/mestiças de aprendizagem, reconhecendo e incluindo "a multiplicidade cultural das populações e a multiplicidade semiótica de constituição dos textos por meio dos quais ela se informa e se comunica" (ROJO, 2012, p. 13). Ademais, a teoria dos multiletramentos propõe a utilização dos recursos das novas tecnologias, a fim de colocar as culturas locais e minorias em contato com os letramentos valorizados (tais como os digitais), assumindo uma função emancipadora para essas culturas menos valorizadas. (ROJO, 2009).

Em consonância com essa teoria educacional, os letramentos críticos (LC), dentre diversos outros objetivos, enxergam o ensino de língua adicional como diretamente conectado à formação cidadã, conceito chave nos processos de internacionalização na academia. Segundo Jordão (2015, p. 73), nos LC “a língua é discurso, espaço de construção de sentidos e representação de sujeitos e do mundo. Os sentidos não são 'dados' por uma realidade independente do sujeito: eles são construídos na cultura, na sociedade, na língua”. Pensar nessa formação consiste, portanto, em considerar, estudar e dialogar com os contextos presentes tanto no universo acadêmico quanto no extra-acadêmico, no qual os alunos vivenciam, de forma intercultural, a proposta do curso do IsF.

Segundo Kalantzis e Cope (2012, p. 149) “O objetivo do letramento crítico é ajudar aprendizes a entender o modo como as coisas são construídas no mundo por valores e ações pessoais". Pensando nos valores democráticos, o ensino de línguas passa a ser um importante meio de transformação da sociedade. Para desenvolver as discussões acerca disso, os autores utilizam Paulo Freire e Donaldo Macedo para promover a prática democrática cidadã,

\footnotetext{
${ }^{9} \mathrm{O}$ inglês como língua franca tem sido amplamente proposto na literatura para o "desenvolvimento de competência intercultural; a ênfase na inteligibilidade [...] bem como a concepção do professor como mediador entre culturas" (SOUZA; BARCARO; GRANDE, 2011, p. 195).
} 
considerando letramentos de pessoas que se tornam sujeitos ativos ao invés de "objetos passivos" de textos.

Kalantzis e Cope (2012) destacam ainda como a construção identitária promovida pelos sujeitos dentro dos LC serve de importante aporte teórico para a pesquisa que realizamos. Considerar a construção identitária se torna essencial uma vez que os LC entendem que toda representação e comunicação envolve identidades humanas que se diferem umas das outras. Segundo os mesmos autores, as identidades são construídas através da validação dos modos de fala e de expressão que são historicamente subjugados em detrimento de um modo hegemônico. Adicionalmente, Kalantzis e Cope (2012, p. 150) ainda afirmam que "Esse tipo de Letramento Crítico também requer às vezes um certo tipo de olhar introspectivo a respeito das posições e atitudes individuais sobre o outro, o diferente: alunos deficientes, de uma orientação sexual diferente, ou de diferente etnia ou grupo social" ${ }^{10}$.

A leitura de Jordão (2015) acerca da temática possibilita um olhar ao processo ideológico que se constrói dentro do letramento crítico, interferindo diretamente nessa construção de identidade e possibilitando um ensino que liberta os sujeitos e dá voz a eles dentro da academia. Dentro do pensamento foucaultiano, no qual a ideologia é entendida a partir de uma perspectiva cultural, social e moral, considerando os sistemas de valores estabelecidos dentro de uma sociedade, a autora afirma que

No LC, a multiplicidade de sentidos possibilitada pelas diversas ideologias é tida como algo produtivo: ao invés de uma realidade por trás da ideologia perniciosa, temos aqui muitas verdades construídas ideologicamente e partilhadas socialmente. Cada uma dessas verdades é considerada melhor ou pior, superior ou inferior às outras conforme se acionem determinados sistemas de valores, determinadas crenças, determinados procedimentos interpretativos ou visões de mundo. (JORDÃO, 2015, P. 76)

Na esteira do que propõe os estudos dos letramentos críticos acerca da identidade, a construção da translinguagem, proposta tanto por García e Wei (2014) quanto por Canagarajah (2013), auxilia na promoção de um espaço onde essas identidades tomam forma linguística e politicamente. Segundo García e Wei (2014, p. 24), esse espaço translíngue, também chamado de thirdspace, quebra a dicotomia entre o macro e o micro, o social e o individual e as relações hegemônicas de linguagem, combinando e gerando novas identidades, práticas e valores. A autora afirma que "O espaço translíngue permite indivíduos multilingues a integrarem espaços

\footnotetext{
10 Tradução livre. Texto original: "This kind of critical literacy also requires at times a certain kind of inwardlooking about one's own stances and attitudes towards the different 'other': students who are disabled, or of a different sexual orientation, or of a different ethnic or racial group".
} 
sociais (e portanto 'códigos linguísticos'), antigamente praticados separadamente em diferentes locais" $" 11$.

O reconhecimento de um espaço onde os discentes podem recorrer a seus repertórios linguísticos, independentemente da língua nomeada utilizada, amplia as possibilidades de comunicação dentro da própria academia, onde negociações de sentido são feitas a todo o momento entre pessoas de diversas culturas e textos de diversos locais.

O desenvolvimento dos LC na formação de cidadãos críticos que lutam por uma sociedade mais igualitária (MONTE MÓR, 2013) pode ser relacionado à translinguagem, uma vez que a entende enquanto ato político (FLORES, 2014) dando abertura para que questões de raça, gênero, classe, sexualidade, cultura, etnia, dentre outras, possam emergir (GARCIA; WEI, 2014). Essas questões também perpassam "múltiplas práticas discursivas que constituem o repertório linguístico dos usuários da língua, tornando visível, através da translinguagem, as diferentes histórias, heranças e ideologias dos usuários multilíngues" ${ }^{12}$ (GARCÍA; WEI, 2014, p. 137).

O estudo da translinguagem aborda, portanto, um reconhecimento de contexto importante tanto para o ensino de línguas para fins acadêmicos, quanto para a promoção da comunicação entre culturas (ambos foco do fenômeno da internacionalização e do curso trabalhado), mesmo que muitas vezes a ênfase desse nicho se volte para uma língua padrão e normatizada. Canagarajah $(2013$, p. 17) ressalta que a ideia de "standard language" é um constructo ideológico e que, por acomodar uma certa hibridez, é importante que aluno utilize os diversos recursos semióticos em seu repertório e utilize do contexto para a produção de uma retórica efetiva para a situação. Portanto, é importante reconhecer não apenas as diversas semioses que estão presentes nessa construção linguística, mas também que "A prática translíngue se aplica mais às estratégias de engajamento com os diferentes códigos, com o cuidado de que o formato do produto textual final vai variar de acordo com as expectativas do contexto"13.

Pensar na perspectiva de construção de sujeitos ativos implica na compreensão de que seu repertório linguístico é visto de maneira não hegemônica e não excludente, ainda que

\footnotetext{
11 Tradução livre. Texto original: "A translanguaging space allows multilingual individuals to integrate social spaces (and thus 'language codes') that have been formerly practiced separately in different places".

${ }^{12}$ Tradução livre. Texto original: "Through multiple discursive practices that constitute the language users' linguistic repertories, translanguaging makes visible the different histories, identities, heritages and ideologies of the multilingual language users".

${ }^{13}$ Tradução Livre. Texto original: "Translingual practice applies more to the strategies of engaging with diverse codes, with the awareness that the shape of the final textual products will vary according to the contextual expectations".
} 
reconheçamos a grande influência da língua inglesa, enquanto língua hegemônica, simbólica para ascensão e inclusão social (RAJAGOPALAN, 2005)

Vale ressaltar que esse reconhecimento não visa à promoção de princípios de mercantilização de habilidades, impulsionada por discursos neoliberais que tentam se apropriar de filosofias teóricas, tal qual a translinguagem. A educação bilíngue, preconizada no presente trabalho, advoga pelo ensino de línguas para o aumento de acesso de seus falantes e o apoio a línguas minoritárias, recusando a forma como tais discursos neoliberais buscam, de forma unilateral, a criação de trabalhadores capazes em uma economia globalizada (POZA, 2017, p. 102).

A esse respeito, destacamos como recentes políticas linguísticas, tal qual a nova Base Nacional Comum Curricular (BNCC) $)^{14}$, em alguns casos com objetivos mercantilistas e utilitaristas, têm priorizado a língua inglesa em detrimento a línguas minoritárias e às particularidades de cada região. E, embora seja dito que programas para o ensino de línguas nas universidades públicas, tais como o Idiomas sem Fronteiras, busquem a valorização das relações interculturais, da inclusão social e do respeito à diversidade sociolinguística, com a inclusão de algumas línguas e cursos que privilegiem a translinguagem, o Ministério da Educação (MEC), por meio da CAPES, disponibiliza bolsas de "residência docente" apenas aos professores-estagiários de língua inglesa ${ }^{15}$.

As políticas linguísticas aliadas aos movimentos migratórios e à internacionalização, do mercado e de ambientes acadêmicos, por exemplo, dão força à translinguagem, particularmente no ensino de língua inglesa, sobretudo por motivos econômicos. Contudo, ao compreendermos as línguas como mutáveis, multimodais e híbridas, nas quais os sentidos "são construídos de forma dinâmica nas relações sociais e são marcados por posicionamentos éticos, estéticos e políticos" (ROCHA \& MACIEL, 2015, p. 8), abrimos espaços de construções identitárias e de conhecimentos que irão questionar as relações de poder e o status quo de temas relevantes à vida discente de forma crítica, defendido pelos LC.

Enquanto isso, e também consoante com os LC e a translinguagem, os multiletramentos também destacam como as novas Tecnologias da Informação e Comunicação (TICs) podem

\footnotetext{
14 O artigo "O componente Língua Inglesa na BNCC” de Vilaço e Grande (2018 no prelo), traz questionamentos relevantes acerca da nova BNCC, que parece ignorar a translinguagem, apresentando retrocessos ao excluir outras línguas, prevalecendo somente a língua inglesa e "desrespeitando as diferenças sócio-históricas e culturais de cada região" (p. 1) do Brasil.

${ }^{15}$ O Núcleo Gestor do Programa IsF, reconhecendo a importância de todos os idiomas oferecidos pelo programa, está empenhado em negociação junto à CAPES para modificar tal situação e oferecer bolsas para professores bolsistas de outros idiomas. Mas ainda não há prazo para isso ocorrer.
} 
otimizar e criar novos significados em uma sociedade em rede (CASTELLS, 1999), em que a cultura digital está inevitavelmente presente no dia-a-dia das pessoas. Cabe ressaltar, no entanto, que dentre as TICs, aquelas destinadas à educação geralmente são dinâmicas e estão em constante mudança, ou então desaparecem muito rapidamente, dando lugar a ferramentas e suportes novos e tidos como mais eficazes. Quando uma nova tecnologia é adotada como inovação em uma escola, o que ocorre é um processo de incorporação, por parte de professores e alunos, de um sistema que pode tanto causar/acelerar mudanças como não ter qualquer efeito (SIGNORINI, 2010). Para que essas novas ferramentas sejam ancoradas por um contexto pedagógico, alinhado a novas perspectivas educacionais, precisamos de cursos e suporte de qualidade para uma geração inteira de professores não nascidos na "era tecnológica", com práticas de letramentos por vezes diferentes das práticas dos alunos.

O contato com o digital pode, portanto, revolucionar os meios de aprendizagem, uma vez que os sujeitos acessam a abstração através dos modos de significação. Segundo Kalantzis e Cope "nós pensamos multimodalmente [...] e pode comumente ser o caso de que nós podemos pensar mais poderosamente quando representamos nossos significados em múltiplos modos" (2012, p. 338). Dessa forma, aprendemos a pensar mais efetivamente ao representar o mundo dentro dessa diversidade semiótica.

Ademais, no caso dos multiletramentos, a diversidade cultural de produção e circulação de textos (nas mais diversas plataformas) e na diversidade de linguagens que esses textos, multimodais, constituem, podem também ser espaços catalisadores do pensamento crítico preconizado no LC, bem como para interatividade e colaboratividade, a transgressão de relações de poder (em especial a questão de propriedade) e o fato dos multiletramentos serem híbridos, fronteiriços e mestiços (de linguagens, modos, mídias e culturas) (ROJO, 2012, p. 23). Segundo a autora, e citando o Grupo de Nova Londres (1996), há portanto essa necessidade de uma pedagogia de multiletramentos por conta da emergência desses novos letramentos na contemporaneidade, onde encontramos "textos compostos de muitas linguagens (ou modos, ou semioses) e que exigem capacidades e práticas de compreensão e produção de cada uma delas (multiletramentos) para fazer significar" (ROJO, 2012, p. 19).

Por fim, é pensando no ensino de línguas como um sistema complexo que engloba as diversas semioses, práticas sociais e práticas pedagógicas, seja no contexto acadêmico ou na formação do sujeito em si, que a teoria dos multiletramentos colabora a partir de um espaço multimodal, expandindo essa prática de ensino de línguas. Os multiletramentos entendem o conhecimento como dinâmico, distribuído e colaborativo, reconhecendo na era digital meios 
em que esse conhecimento pode ser construído por e para os sujeitos envolvidos. Dito isso, o modo em que os alunos interagem com as multissemioses deve estar presente no pensar do preparo das aulas e na maneira de aplicação, pois como afirma Duboc $(2007$, p. 266) "No novo contexto multimodal, o processo de (re)criação e negociação de sentidos torna-se mais complexo, requerendo o desenvolvimento de estratégias e habilidades mais diversificadas e, conseqüentemente, uma pedagogia que responda a tais demandas".

\section{Análise e resultados}

Diante dos oito planos de aula criados por André, a prática docente foi analisada em relação às perspectivas dos letramentos críticos, da translinguagem e dos multiletramentos. Tais teorias auxiliam professores a trabalhar a transformação pessoal e social, refletir sobre os valores vigentes pelas culturas e ainda promover um sujeito ativo, crítico e participativo que reconhece seu lugar perante a hegemonia da língua inglesa dentro das diversas plataformas de construção de saber. É pensando no diálogo entre essas teorias que o estudo das três perspectivas do artigo contribui para o ensino de língua inglesa e promove a internacionalização acadêmica. Também discutiremos como tais perspectivas participam na ampliação do repertório linguístico dos discentes.

A tabela a seguir apresenta as temáticas das aulas preparadas para o curso ministrado. As atividades foram pensadas a partir de temáticas que possibilitam o pensamento crítico e a problematização dos assuntos. O preparo foi alinhado às perspectivas educacionais já discutidas, contribuindo também para a produção final planejada.

\begin{tabular}{|c|c|c|c|}
\hline AULA & TEMÁTICA & PERSPECTIVA & MÍDIAS \\
\hline Aula 1 & Apresentação e avaliação diagnóstica & Translinguagem & -- \\
\hline Aula 2 & $\begin{array}{l}\text { Preconceito linguístico ligado à raça e } \\
\text { contexto de uso da língua }\end{array}$ & $\begin{array}{l}\text { Letramentos críticos, } \\
\text { multiletramentos e } \\
\text { translinguagem }\end{array}$ & Vídeo \\
\hline Aula 3 & Racismo e visão colonial da narrativa & $\begin{array}{l}\text { Letramentos críticos e } \\
\text { multiletramentos }\end{array}$ & $\begin{array}{l}\text { Vídeo com suporte do } \\
\text { texto literário }\end{array}$ \\
\hline Aula 4 & Gênero e sexualidade & $\begin{array}{l}\text { Letramentos críticos e } \\
\text { multiletramentos }\end{array}$ & Música e vídeo \\
\hline Aula 5 & $\begin{array}{l}\text { Diversidade cultural e } \\
\text { comportamentos }\end{array}$ & $\begin{array}{l}\text { Letramentos críticos e } \\
\text { multiletramentos }\end{array}$ & Vídeo \\
\hline Aula 6 & Gênero podcast e os recursos que o & Multiletramentos & Podcast \\
\hline
\end{tabular}




\begin{tabular}{|c|c|c|c|}
\hline & englobam (apresentação do gênero) & & Podcast \\
\hline Aula 7 & Preparo da produção final & $\begin{array}{c}\text { Multiletramentos/ letramento } \\
\text { digital e translinguagem }\end{array}$ & Podcast \\
\hline Aula 8 & Apresentação da produção final & $\begin{array}{c}\text { Letramentos críticos, } \\
\text { multiletramentos/ letramento } \\
\text { digital e translinguagem }\end{array}$ & \\
\hline
\end{tabular}

Tabela 1 - Relação entre as aulas, temáticas, perspectivas teóricas foco e mídias trabalhadas.

As 8 aulas planejadas englobam o contexto acadêmico e cultural, tanto por meio da leitura do texto literário alinhada aos suportes midiáticos, como das produções textuais multimodais, dinâmicas de interação e discussões orais. Uma análise mais aprofundada explorará, portanto, como essas perspectivas teóricas impactam a experiência cultural e linguística dos discentes no curso em questão

\subsection{Aulas 1 e 2 e a construção do espaço confortável ao aprendiz de língua inglesa}

Para a compreensão do real contexto de proficiência a ser experienciado no curso, na primeira aula foi feita uma avaliação diagnóstica de cunho oral, em que a dinâmica de apresentação contribuiu para o pensar efetivo das aulas posteriores. Uma vez que o Common European Framework of Reference for Languages é definido para o ingresso no programa pelo nivelamento do My English Online ou a nota do TOEFL ITP, onde não há exigência de uma avaliação oral, o processo de avaliação diagnóstica se torna essencial para o professor conhecer melhor a proficiência oral da turma. Da mesma forma, como muitos alunos "acabam de regressar" de um período ocioso de prática, a atividade de interação proposta também funciona como um icebreaker, dando início a construção de um espaço confortável de fala ou thirdspace, como proposto por García e Wei (2014).

A segunda aula contou com a apresentação de um vídeo intitulado “Three Ways to Speak English" (Ted Talk interpretado poeticamente por Jamila Lyiscott) problematizando questões linguísticas e as relações de poder das línguas, validando modos de fala subjugados e abrindo a discussão e reflexão para a problematização linguística. Através da atividade, foi possível abrir a discussão para o contexto de fala dos próprios alunos, que passaram a questionar o contexto linguístico acadêmico em que se encontram, reconhecendo situações de preconceito linguístico (BAGNO, 2015) e entendendo que todas as línguas possuem variantes e instituições que a normatizam.

A abertura para tais discussões auxilia na formação desse espaço, o thirdspace, onde “diferenças podem ser mostradas livremente e negociadas ativamente" e ainda ser um "espaço 
colaborativamente construído para aceitar as diferenças" (CANAGARAJAH, 2013, p. 85) conforme o próprio depoimento de André:

\begin{abstract}
Tal espaço foi, portanto, construído por e com os discentes através de perguntas de interpretação e compreensão de texto como "O que significa ser "articulado" para você? E para Jamila?" e "Como esse tema se aplica à sua realidade?", ampliando a noção linguística acerca de alguns termos usados pela palestrante e ainda dando espaço aos alunos para discutir o tema dentro de sua própria realidade, problematizando linguisticamente o próprio universo.

Entrevista André - 5 de outubro de 2018
\end{abstract}

O discurso de Jamila, dentro do TedTalk apresentado em aula e comentado por André, contribui principalmente para a formação de uma prática linguística que respeite o falante e seu espaço de enunciação. A aula faz jus, portanto, ao letramento crítico proposto, uma vez que parte do entendimento de que a língua é ideológica, política e identitária, provocando uma reflexão crítica relacionada aos diferentes contextos de enunciação, inclusive os deles próprios. A construção e discussão dos temas em aula refletiu no posicionamento político dos alunos, fazendo com que se sentissem mais confortáveis com os momentos de fala, pois não mais os entendiam como momentos de deixar de lado a própria identidade para se comunicar em uma outra língua. Esse trabalho refletiu também nas produções finais, apresentando diversos "rhetorical strengths" nos discursos, como se pode observar no exemplo a seguir.

ELLEN $^{16}$ : Nice, eh... It's easy, porridge is something easy, it's because of this that sometimes I bring to university. I can do in 10 minutes or less than this. It's amazing! Top! Top!

(ELLEN: Legal, eh... É fácil, mingau é algo fácil, é por causa disso que às vezes o trago para a universidade. Eu consigo fazer em 10 minutos ou menos que isso. É incrível! Top! Top!)

Podcast The Brazilian way of eating - minutos 7:35 a 7:50 - Produção final colaborativa

O exemplo retirado de um dos podcasts produzido por dois alunos do curso exemplifica o impacto das duas primeiras aulas. A discente aparenta estar confortável em sua fala, trazendo suas práticas da vida universitária para a produção e utilizando gírias. Poderíamos, portanto, assumir que esse espaço de segurança (safe space) foi construído especialmente pela forma que o acadêmico-professor, sobretudo a partir dessas duas primeiras aulas, cria uma atmosfera propícia para tal. Analisamos também que a aluna parece não se sentir acuada com a norma padrão adotando o estilo talk show, assim como o gênero podcast pede, e com as regras gramaticais que não emprega corretamente (levando-se em conta o seu nível intermediário de proficiência). O termo destacado em negrito evidencia ainda a decisão de manter a expressão, que por mais que tenha origem na língua inglesa, é utilizada como uma interjeição coloquial

\footnotetext{
${ }^{16} \mathrm{O}$ nome da aluna foi alterado para um nome fictício para garantir o anonimato dela.
} 
comum entre jovens brasileiros, mantendo a identidade e utilizando a translinguagem dentro do que é aceito pelo gênero proposto.

\subsection{Aulas 3, 4 e 5: tópicos sensíveis culturalmente e a construção identitária em narrativas brasileiras}

Assim como apresentado anteriormente, a ementa do curso de Comunicação Intercultural do IsF já prevê o trabalho com tópicos sensíveis a determinadas culturas. Desta forma, as aulas 3, 4 e 5 trabalham questões sociais importantes para a internacionalização acadêmica, formação cidadã e reflexão sobre comportamentos humanos, reunindo um pensar que constitui a produção como uma ação de sujeitos ativos. As produções perpassam a formação da identidade brasileira e temas sensíveis relacionados, não apenas informando, mas reconhecendo a importância de se pensar tais temáticas no próprio contexto histórico-cultural.

A aula 3, que aborda a temática de racismo e narrativa africana, trabalhou com a leitura do conto Jumping Monkey Hill de Chimamanda Ngozi Adichie, escritora africana e negra da literatura contemporânea. O conto permitiu o desenvolvimento não apenas da competência da leitura, através de estratégias essenciais para o letramento acadêmico e a materialidade da língua inglesa, mas também abriu espaço para o diálogo a respeito do olhar colonizador e ocidental de se contar a narrativa africana. Para o desenrolar do debate, a exibição do vídeo The Danger of a Single Story (Ted Talk ministrado pela própria autora do conto supracitado) auxiliou na discussão complementando o pensamento crítico já desenvolvido com a leitura feita. Dentre os apontamentos levantados pelos alunos, a leitura do ponto de vista colonizador, que só reconhece a narrativa africana a partir do ponto de vista catastrófico, foi um dos maiores ganhos da aula, segundo os próprios discentes, que trouxeram apontamentos de partes que mais os chamaram atenção. Segundo André, por exemplo, o trecho abaixo recebeu uma atenção especial pelos próprios alunos, que se reconhecem em um tema contemporâneo (a sexualidade humana) e puderam associar a narrativa africana com a própria narrativa ocidental, de modo a aproximála do ponto de vista humano e descolonial.

\footnotetext{
After dinner, the Senegalese read from her story. It was a windy night and they shut the door to keep out the sound of the whirling trees. The smoke from Edward's pipe hung over the room. The Senegalese read two pages of a funeral scene, stopping often to sip some water, her accent thickening as she became more emotional, each $t$ sounding like a z. Afterwards, everyone turned to Edward, even the Ugandan, who seemed to have forgotten that he was workshop leader. Edward chewed at his pipe thoughtfully before he said that homosexual stories of this sort weren't reflective of Africa, "Which Africa?" Ujunwa blurted out. really. (ADICHIE, 2017, p. 107-108)
} 
Da mesma forma, a aula 4 abordou questões de gênero e sexualidade através da música Sex Yeah da cantora galesa Marina and The Diamonds e o vídeo do youtuber americano Tyler Oakley intitulado A Matter of Life or Death: LGBTQ+ Refugees. O uso dos dois artefatos culturais trabalham a multiplicidade semiótica na construção linguística, fornecendo pano de fundo para a discussão de temática cara às culturas abordadas em aula.

O tema trabalhado serviu também como norte conceituador, pois a configuração plural da turma apresentou dificuldades com relação à distinção entre gênero e sexualidade, termos essenciais para a discussão sobre sexismo e homofobia, uma vez que ambos os termos se relacionam por conta dos papéis sociossexuais pré-estabelecidos (BORRILLO, 2010, p. 26).

A música trabalhada contou com uma atividade onde os alunos deveriam preencher lacunas que completariam com termos e palavras importantes para a discussão da aula. $\mathrm{O}$ conteúdo de "Sex Yeah" levantou primeiramente o questionamento conceitual à respeito do termo "sexo" em oposição ao adotado hoje em dia, "gênero", levando os alunos a debaterem, inclusive, questões históricas sobre o feminismo e outras contribuições advindas do movimento. Após o debate e a conceituação de termos levantados e respondidos pelos próprios discentes com a mediação do professor, o vídeo utilizado reuniu a problemática apresentando dois casos de refugiados nos Estados Unidos (um homem que constituíra família no país e uma mulher vítima de perseguição em detrimento de sua sexualidade). Após a exibição do vídeo, a pergunta “A sexualidade é também influenciada pela cultura? De quais maneiras?” ampliou a discussão e o vocabulário a respeito do tema, permitindo aos alunos uma produção oral a partir de um texto que eles não mais decodificam apenas, mas dialogam ativamente em rede de significações críticas. O tema foi, portanto, catalisador e fomentador para a discussão das diferenças culturais e para uma outra forma de se ler um texto.

Por fim, as diferenças culturais, trabalhadas nas duas aulas, são trabalhadas a partir da discussão sobre comportamentos na aula 5, através do vídeo Top 10 American Customs That May Be Offensive In Other Countries. A atividade teve base na compreensão do vídeo, na tomada de notas e na apresentação de cada costume cultural atrelado ao comportamento que os próprios alunos tinham dentro da diversidade cultural brasileira. A temática impulsionou a proposta do curso, Comunicação Intercultural, apresentando aos alunos a produção final como sendo uma gravação de podcast sobre diferenças culturais a partir do ponto de vista dos brasileiros.

A proposta de produção final retoma, por um lado, as questões sensíveis trabalhadas e, por outro, a questão da problematização linguística construída no começo do curso, reforçando 
a ação do letramento crítico, da translinguagem e a teoria dos multiletramentos, base para a produção final. A questão de gênero é retomada por dois alunos no podcast produzido a respeito do dia internacional da mulher e o racismo aparece no podcast dedicado à diversidade religiosa no Brasil, retomando a questão histórica de opressão, reunindo informações pesquisadas pela aluna responsável, trabalhando as religiões africanas que constituem nossa cultura. A questão linguística esteve presente em todas as produções, propondo aos alunos a ideia de um podcast em inglês, porém narrado e produzido por brasileiros que o têm como segunda língua. Por conta disso, as produções contaram com a presença do thirdspace, evidenciando a identidade linguística e as escolhas lexicais e semióticas feitas pelos alunos.

\subsection{Aulas 6, 7 e 8: trabalho com o gênero podcast}

Como propõe a teoria dos multiletramentos, a aula 6 foi dedicada à apresentação do gênero podcast, uma vez que a produção final exige uma familiarização a ele; uma nova ética e novas estéticas (ROJO, 2012, p. 16). Nessa aula, os alunos puderam reconhecer as especificidades do gênero proposto, identificando as diferenças em relação aos gêneros já trabalhados (como o vídeo, a música e o texto literário) e os formatos possíveis dentro do podcast. Além disso, os discentes debateram e reconheceram os instrumentos técnicos (gravador de voz, aplicativo de edição) necessários para criação daquele texto. A análise de dois artefatos do gênero proposto: What's the tee?: Halloween e Indefensible: Fighting to be with people you love, resultou na construção de 1 podcast no formato talk show (formato do primeiro podcast) e outros 5 no formato documentário (apresentado no segundo podcast). Nesse sentido, as produções atenderam às especificidades do gênero, uma vez que a pedagogia dos multiletramentos foi aplicada, conforme abaixo:

Resumidamente, tratava-se de formar um usuário funcional que tivesse competência
técnica ("saber fazer") nas ferramentas/textos/práticas letradas requeridas, ou seja,
garantir os "alfabetismos" necessários às práticas de multiletramentos (às ferramentas,
aos textos, às línguas/linguagens). Mas esse patamar, claramente, não basta a essa
"pedagogia": a questão é alfabetismos funcionais para que (e em favor de quem).
(ROJO, 2012, p. 29)

A aula 7, por sua vez, foi dedicada à preparação, orientação e construção das produções. Nessa aula, a construção identitária do podcast (elemento observado pelos próprios alunos na aula anterior) foi criada a partir de uma produção textual coletiva referente ao nome do podcast e à apresentação de abertura. Os alunos abraçaram o projeto, adotando uma postura autônoma em relação às produções, coletiva em relação ao trabalho em grupo e à elaboração do projeto 
como um todo e identitária na adoção de uma postura de "agentes construtores", sujeitos ativos, na produção:

Confrontando procedimentos interpretativos no espaço escolar, em um ambiente de colaboração, os alunos têm a oportunidade de perceber-se na posição de atribuidores de sentidos, de se ver como agentes construtores de significados em conjunto com comunidades discursivas de interpretação. (JORDÃO, 2015, p. 84)

Com esse propósito, o título dos podcasts foi escolhido como: "The Brazilian way

of ...", ficando a cargo de cada grupo, responsável por determinada temática, completar o título de acordo com o conteúdo do "episódio" gravado. Foi observado, portanto, que as construções dos podcasts adotaram uma posição ideológica quanto às construções de identidades das produções. O thirdspace proposto por García e Wei (2014) se mostrou de maneira evidente nesse espaço onde os alunos se sentiram confortáveis para recorrer ao próprio repertório multissemiótico na construção de sentidos: em The Brazilian Way of Religion, a aluna recorre a músicas africanas que utilizam do berimbau e outros instrumentos que dão o tom necessário para a compreensão das religiões apresentadas; e em The Brazilian Way of Music, ao apresentar os gêneros musicais ouvidos no Brasil, os alunos utilizam de trechos de canções de cada gênero (sertanejo, sertanejo universitário, mpb, samba e pagode), produzindo não só o sentido do texto como um todo, mas também o efeito persuasivo do discurso.

Feita toda a produção, a aula 8 foi dedicada finalmente à apreciação das produções feitas por eles mesmos. Foi, portanto, um espaço de empoderamento e de validação das multiplicidades de vozes presentes na turma. Os alunos puderam ouvir os colegas através de suas produções, discutir as temáticas em grupo e trabalhar o feedback, incentivando a prática multimodal como um modo de aprendizado de fato.

\section{Considerações finais}

Analisando os planos ministrados, foi possível identificarmos a formação cidadã proposta pelo letramento crítico refletida tanto no repertório cultural quanto linguístico evidentes nas discussões orais e nas produções finais em gênero podcast. $\mathrm{O}$ trabalho com questões sensíveis refletiu inclusive nas temáticas adotadas pelos discentes em seus trabalhos que contaram como nota de conclusão para o curso. Adicionalmente, eles apresentaram um resultado que excedeu expectativas também no que diz respeito à satisfação dos próprios alunos, que se viram capazes de produzir um conteúdo que aborda temas tidos até então como de complexo desenvolvimento em uma língua adicional.

Para a produção dos podcasts, foi trabalhado o letramento digital que supriu a necessidade dos alunos de acessar um repertório linguístico e semiótico característico dos 
gêneros utilizados. Essas contribuições refletem na formação crítica desses alunos que, inseridos em ambiente acadêmico, muitas vezes se veem limitados à produção acadêmica textual grafocêntrica, além de contribuir para a discussão de temas que não são trabalhados no cotidiano exigido pela academia.

No que diz respeito à prática docente, o presente trabalho evidencia, sobretudo, a necessidade de se pensar o planejamento dos cursos de maneira a unir a prática à teoria em uma transposição didática que atenda às demandas exigidas tanto pela ementa já prevista no curso, quanto pelas questões que emergem na sociedade global e, principalmente, local de cada contexto. Aliadas, portanto, às práticas multiletradas, os textos ganham um debate mais rico que explora a multiplicidade de vozes, de identidades, de significações e de produção textual, compreendendo competências essenciais no ensino de línguas.

É, portanto, de suma importância que a transposição didática seja pensada como um modo de transformar a prática docente e as aulas de língua inglesa dentro do ambiente acadêmico. Se mostra evidente o diálogo entre teorias que contribuem para um curso linguística e culturalmente diverso, preparando não apenas o aluno para possibilidades de comunicação que perpassam a prática dialógica ideológica com outras culturas, mas contribuindo também para possibilidades futuras de interação e construção de conhecimentos, considerando os repertórios linguísticos e culturais diversos, em particular dentro do IsF, que tem buscado trocas comunicativas e acadêmicas transdisciplinares, que vão ao encontro das perspectivas educacionais aqui mencionadas e utilizadas nos planejamentos analisados.

\section{Referências bibliográficas}

BAGNO, Marcos. Preconceito Linguístico. São Paulo: Parábola Editorial, 2015.

BORRILlO, Daniel. Homofobia: História e crítica de um preconceito. Belo Horizonte: Autêntica, 2010.

BRASIL, Ementa do curso "Comunicação Intercultural” do Idiomas Sem Fronteiras, 2017. Disponível em: http://isf.mec.gov.br/. Acessado em 10 de agosto de 2018.

CANAGARAJAH, Suresh. Translingual Practice: Global Englishes and Cosmopolitan relations. Nova Iorque: Routledge, 2013.

CASTELLS, Manuel. A sociedade em rede - A era da informação: economia, sociedade e Cultura. Vol. 1. São Paulo: Paz e Terra. 2010.

FLORES, Nelson. Let's not forget that translanguaging is a political act. Disponível em: http://educationallinguist.wordpress.com/2014/07/19/lets-notforget-that-translanguaging-is-apolitical-act/. Acessado em: 19 de julho de 2014. 
DUBOC, Ana Paula Martinez. A avaliação da aprendizagem de língua inglesa segundo as novas teorias de letramento. Fragmentos, número 33, p. 263-277 Florianópolis/ jul - dez/ 2007. Disponível em: https://periodicos.ufsc.br/index.php/fragmentos/article/viewFile/8669/8010. Acessado em: 22/09/2018.

GARCÍA, Ofelia; WEI, Li. Translanguaging: Language, Bilingualism and Education. Nova Iorque: Palgrave Macmillan, 2014.

JORDÃO, Clarissa. Abordagem comunicativa, pedagogia crítica e letramento crítico - farinhas do mesmo saco? In: ROCHA, Cláudia Hilsdorf; MACIEL, Ruberval Franco. Língua Estrangeira e Formação Cidadã: Por entre Discursos e Práticas. Campinas: Pontes Edital, p. 69-90 2013.

KALANTZIS, Mary; COPE, Bill. Literacies. Londres: Cambridge University Press, 2012.

LEWIS, Gwyn.; JONES, Bryn.; BAKER, Colin. "Translanguaging: Developing its conceptualisation and contextualisation." Educational Research and Evaluation. V 18, no. 7, p. 655-670. 2012.

MONTE MÓR, Walkyria Maria. "Crítica e letramentos críticos: reflexões preliminares." In: ROCHA, Cláudia Hilsdorf; MACIEL, Ruberval Franco. Língua Estrangeira e Formação Cidadã: Por entre Discursos e Práticas. Campinas: Pontes Editora, p. 31-50, 2013.

PENNYCOOK, Alastair. Global Englishes and transcultural flows. London: Routledge, 2007.

POZA, Luis. "Translanguaging: Definitions, Implications, and Further Needs in Burgeoning Inquiry." Berkeley Review of Education 6, no. 2. 2017.

RAJAGOPALAN, Kanavillil. A geopolítica da língua inglesa e seus reflexos no Brasil: por uma política prudente e propositiva. In: LACOSTE, Y.; RAJAGOPALAN, K. (Orgs.). A geopolítica do inglês. São Paulo: Parábola Editora, 2005, p.135-159.

ROCHA, Cláudia Hilsdorf.; MACIEL, Ruberval Franco "Ensino de língua estrangeira como prática translíngue: articulações com teorizações bakhtinianas." DELTA: Documentação e Estudos em Linguística Teórica e Aplicada. V. 31, no. 2, 2015.

ROJO, Roxane. Pedagogia dos multiletramentos: diversidade cultural e de linguagens na escola. In: ROJO, Roxane; MOURA, Eduardo [orgs]. Multiletramentos na Escola. São Paulo: Parábola Editorial, 2012. p. 11-31.

Letramentos múltiplos, escola e inclusão social. São Paulo: Parábola Editorial, 2009.

TURNER, Marianne.; LIN, Angel M. Y. "Translanguaging and named languages: Productive tension and desire." International Journal of Bilingual Education and Bilingualism. p. 1-11. 2017.

SIGNORINI, Inês. Inovação e Letramento digital. Seminário do GEL, 2010. São Carlos.

SOUZA, Adriana Grade Fiori.; BARCARO, Carla.; GRANDE, Gabriela Claudino. As representações de alunas-professoras de um curso de Letras sobre o estatuto do inglês como língua franca. In: GIMENEZ, T. N.; CALVO, L.C.S.; EL KADRI, M.S.-.Inglês como língua franca: Ensino-aprendizagem e formação de professores. Coleção: Novas Perspectivas em Linguísticas Aplicada Vol. 14. Campinas, SP: Pontes Editores, 2011. 
Recebido em 06 de dezembro de 2018. Aceito em 18 de janeiro de 2019. 